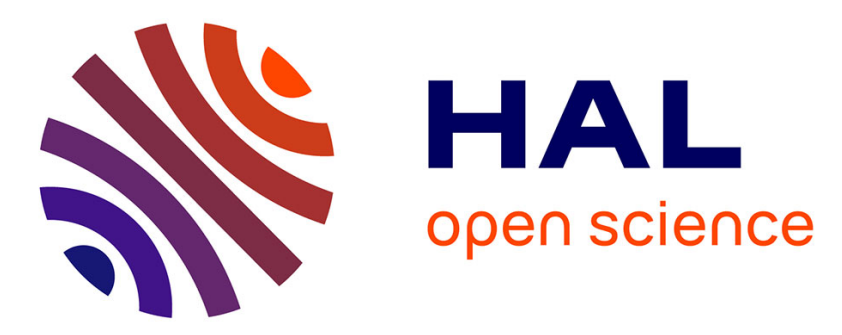

\title{
From 3D grassy vegetation point cloud to hydraulic resistance: Application to close-range estimation of Manning coefficients for intermittent open channels
}

F. Vinatier, Jean-Stéphane Bailly, Gilles Belaud

\section{- To cite this version:}

F. Vinatier, Jean-Stéphane Bailly, Gilles Belaud. From 3D grassy vegetation point cloud to hydraulic resistance: Application to close-range estimation of Manning coefficients for intermittent open channels. Ecohydrology, 2017, 10 (8), pp.e1885. 10.1002/eco.1885 . hal-01598882

\section{HAL Id: hal-01598882 \\ https://hal.science/hal-01598882}

Submitted on 30 Sep 2017

HAL is a multi-disciplinary open access archive for the deposit and dissemination of scientific research documents, whether they are published or not. The documents may come from teaching and research institutions in France or abroad, or from public or private research centers.
L'archive ouverte pluridisciplinaire HAL, est destinée au dépôt et à la diffusion de documents scientifiques de niveau recherche, publiés ou non, émanant des établissements d'enseignement et de recherche français ou étrangers, des laboratoires publics ou privés. 


\title{
From $3 D$ grassy vegetation point cloud to hydraulic resistance: Application to close-range estimation of Manning coefficients for intermittent open channels
}

\author{
F. Vinatier ${ }^{\mathrm{a}, *}$, J.-S. Bailly ${ }^{\mathrm{b}}$, G. Belaud ${ }^{\mathrm{c}}$ \\ ${ }^{a}$ INRA, UMR LISAH, F-34060 Montpellier, France \\ ${ }^{b}$ AgroParisTech, UMR LISAH, F-34060 Montpellier, France \\ ${ }^{c}$ SupAgro, UMR GEAU, F-34093 Montpellier, France
}

\begin{abstract}
The understanding of interrelations between biotic and abiotic processes in intermittent open-channels is currently of primary importance to better assess the services and disservices they provide. A large body of literature attempts to characterize vegetation functional traits affecting hydraulic rugosity, through the introduction of the blockage factor of flow by vegetation. However, this factor has multiple definitions and is still difficult to assess in the fields with actual and diverse vegetation covers, especially for grassy plants of ditches. Our study aims at predicting flow resistance from $3 D$ vegetation characteristics using a close-range laser scanner. Flow resistance and vegetation $3 D$ characteristics were defined using Manning coefficient and blockage factors, respectively. We tested combined effects of flow discharge against plant species and densities characterizing intermittent channels in a channel flume. Our results showed a variability of Manning coefficient describing flow rugosity against species and densities, with a highest rugosity for sclerophyllous species than herbaceous ones. Different blockage factors were calculated on the basis of scan clouds linked to Manning coefficients using non linear equation. The best relationship $\left(R^{2}=0.9\right)$ were found for non linear equation relating Manning coefficients to a simplified blockage factor figuring the mean vegetation height deduced from the projection of the scan point cloud to the channel frontal area. The introduction of a coefficient to correct underestimated values issued from herbaceous species considering their reconfiguration under hydrodynamic loading is thus discussed.
\end{abstract}

Keywords: plant architecture, Terrestrial Lidar Scanner, 3D, hydraulics, ditch,

\section{Highlights}

- We built a hydraulic experimental setup composed of real ${ }_{21}^{20}$ plants frequently found in Mediterranean ditches in a channel flume to analyze the effect of vegetation diversity and ${ }_{23}$ density on hydraulic resistance.

- We used a scanner laser to measure vegetation point clouds ${ }^{25}$ and estimate several blockage factor induced by vegeta- ${ }^{26}$ tion cover.

- The blockage factor explained $90 \%$ of flow resistance de- 29 duced from the total head loss at the channel scale.

- The results we found allow the objective pre-determination of resistance factors for intermittent grassy open-channels ${ }_{33}$ (irrigation channels, drainage ditches) using close-range vegetation size estimation technics.

\section{Introduction}

Intermittent open-channels in cultivated landscapes consist of irrigation channels, road-side ditches, drainage ditches and ${ }_{40}$ reshaped gullies that have been built for centuries (Lepart \& ${ }_{41}$

\footnotetext{
${ }^{*}$ Corresponding author

Email address: fabrice.vinatier@supagro.inra.fr (F. Vinatier)
}

Debussche, 1992) to convey water to plots or conversely, to catch the excess of water from plots or roads and convey them to rivers. They are mainly made of soft soil material where vegetation can grow, requiring channel vegetation management (Levavasseur et al., 2014).

As a consequence, the vegetation of intermittent open-channels and its dynamics could provide numerous ecosystem disservices and services (Dollinger et al., 2015) by affecting the former channel hydraulic conveyance capacities, by trapping and tranporting sediments, nutrients and pollutants, making them biogeochemicals hotspots in addition to be ecological hotspots (Herzon \& Helenius, 2008).

In turn, intensities of these services and disservices result from complex interrelations between biotic and abiotic processes (Wiens, 2002; Thomas et al., 2014), governed by channel hydraulics (flow height, residence time, flow velocity field) depending on plant functional traits (Kouwen et al., 1969) such as the drag at the blade or plant scale, or integrated resistance factors at the patch or reach scales. The study of plant functional traits of interest (e.g. plant size and architecture), are usually carried out by agro-ecological insights (Colbach et al., 2014) but it also appears of primary importance to conduct researches at the interface between ecology and hydrology in order to study the diversity of plant functional traits against water flows (Nikora, 2010).

The link between vegetation and flow chacteristics is the 
subject of many studies in eco-hydraulics reviewed by Curran 58 \& Hession (2013); Nepf (2012); Vargas-Luna et al. (2015). In 59 particular, it was shown that vegetated channel flows could be 60 approached with Nikuradse (1933)'s model, making the link be- 61 tween local shear stress and velocity distribution (Stephan \& 62 Gutknecht, 2002).

Many studies can be found in the literature, linking veg- 64 etation characteristics to local flow properties (Järvelä, 2005; 65 Luhar \& Nepf, 2013). Vargas-Luna et al. (2015) analyzed per- 66 formances of hydraulic models on 13 and 27 experimental stud- 67 ies linking flow resistance to real and artificial vegetation, re- 68 spectively. Vegetation effects on flows were deduced from the 69 rigid-cylinder analogy that considered a characteristic diame- 70 ter, average height and distance between plant similar for each 71 experiment.

Applying these concepts to real systems raises major issues, 73 such as the characterisation of vegetation properties, the effect 74 of vegetation heterogeneity, or the upscaling from plant scale to 75 reach scale (Folkard, 2011).

Advances have been done at plant scale by Weissteiner et al. 77 (2015) and Jalonen \& Järvelä (2014), thanks to an original setup 78 implying a towing tank and fully digitized riparian trees, they 79 explored the plant reconfiguration under hydrodynamic load- 80 ing. Cassan et al. (2015) could show the good correspondence 81 between local shear stress and reach scale resistance, but veg- 82 etation properties could be estimated only indirectly through 83 their effect on flow characteristics. Flows with emergent veg- 84 etation typical of intermittent channels were much less investi- 85 gated, notably because of the difficulty to explore velocity fields 86 within the vegetation (Pasquino et al., 2016), despite some ad- ${ }_{87}$ vances in this field using numerical experiments (Boothroyd ${ }_{88}$ et al., 2016).

Green (2005b) summarized the main concepts to calculate 90 the resistance in the light of the nature and size of vegetation, 91 and obtained a non-linear relationship between channel resis- 92 tance and the proportion of the channel occupied by vegetation, 93 suggesting its first order effect on flow resistance.

However, the vegetation resistance cannot be observed di- 95 rectly: it is empirically calibrated and rarely defined at the reach 96 scale. Green (2005a) identified the vegetation size parameters, 97 usually resumed in a "blockage factor" included in different for- 98 mulations of roughness estimation due to vegetation (Fisher, 99 1992). Blockage factor covers different vegetation size metrics 100 and scales. It initially denoted at a given abscissae of the reach,101 the cross-sectional blockage factor consisting of the proportion ${ }_{102}$ of the wetted cross-section occupied by plant stands (Watson,103 1987; Jalonen et al., 2014). When sampled regularly along the reach, it corresponds at reach scale to the average ponctual cross-sectional blockage factors (Champion \& Tanner, 2000).

It results now multiple definitions of vegetation size met-105 rics linked to resistance parameters at reach scale with different ${ }_{106}$ levels of difficulties to estimate it. This latter point lead Green ${ }_{107}$ (2005b) to conclude that surface area blockage factor had to 108 be preferred, since measuring the vegetation size, especially at ${ }_{109}$ patch, stand or reach scale is a difficult task that depends on ${ }_{110}$ vegetation complexity. Recently, a large amount of litterature ${ }_{111}$ attempted to approach the blockage factor using direct mea-112 sures in the fields and in the laboratory, depending on plant type. The Leaf Area Index (LAI) or the leaf to stem area ratio was introduced as a vegetation density measure of the blockage factor (Jalonen et al., 2012; Jalonen \& Järvelä, 2014) for woody vegetation. Jalonen et al. (2015) characterized the mixed foodplain vegetation in order to derive metrics for hydraulic analyses. They found that mean heights of vegetation were best related to their frontal areas for herbaceous vegetation whereas a complete view of their 3D structure was necessary for woody plants.

The recent spread of Terrestrial Laser Scanner (TLS) offers possible vegetation size estimations from in-field experiments for hydraulic applications (Jalonen et al., 2012, 2015; Boothroyd et al., 2016). The TLS helped characterizing the height distribution and the volumetric blockage factor of plant communities at channel scale (Jalonen et al., 2014, 2015), or the complete morphology of single trees (Boothroyd et al., 2016).

To our knowledge, although the empirical evidence of considering vegetation properties to infer flow transport (VargasLuna et al., 2015), and the potential of using TLS for pre-determination of reach roughness parameters (Jalonen et al., 2015), there is no empirical study linking vegetation point clouds derived from TLS scans to open-channel roughness coefficients, and especially for grassy plants that can be found in intermittent open channels of cultivated landscapes. Grassy plants have a small size and a large range of morphological variability and flexibiliy among species (Kattge et al., 2011), ranging from the herbaceous ones, very flexible, to the sclerophyllous plants that had hard leaves and/or stems.

This paper aims at investigating how different channel vegetation size metrics estimated from scanner laser point clouds may lead to the estimation of Manning roughness coefficient resulting from total head loss during steady flow. The study is based on original experiments using actual grassy plant material, both herbaceous and sclerophyllous, installed in a flume with controlled hydraulic conditions. The main originality of the paper comes from the attempt to link real grassy vegetation clouds to Manning roughness coefficients.

We first expose the factorial experimental setup regarding flow discharge, plant species and plant densities implemented on the channel bed. The different vegetation size metrics at the reach scale from scanner-laser data are then exposed. We finally test the statistical modelling between vegetation metrics and Manning coefficients. Results are then discussed in comparison to those obtained by Green (2005b) and (Jalonen et al., 2015; Jalonen \& Järvelä, 2014).

\section{Material and methods}

\subsection{The experimental flume}

Experiments were conducted in a channel with cement borders of length $13 \mathrm{~m}$, width $0.67 \mathrm{~m}$, and depth $0.40 \mathrm{~m}$, located in the hydraulic laboratory of Montpellier, Supagro (43.62N, $3.85 \mathrm{~W}$ ) (Figure 2). The channel was chosen according to its dimensions similar in terms of geometry and Froude number to agricultural ditches of the Languedoc vineyards area, avoiding scale effects. The downstream water level was imposed by 
a rectangular weir. Flow turbulencies were minimized using a 57 flow tranquilizer located upstream (Figure 1). The channel bot- 58 tom was covered with high-density polystyrene plates pierced 59 at a density of 328 holes. $m^{-2}$ arranged on a regular grid. Holes 60 were filled with plastic dowels to facilitate plants push down 61 and manipulation.

The channel slope $S_{b}$ was $1.3 / 1000$. The discharge was 63 maintained constant thanks to level control structures and baf- 64 fle sluice gates located upstream of the flume. Discharges were 65 checked by velocity integration on the wetted area (10 verticals, 66 5 points per vertical). Local velocities were explored using a 67 current meter (Hydreka@M801). The two selected flow rates 68

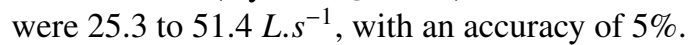

Water depth was measured using point gauges installed at 70 the upstream end, the middle and the downstream end of the 71 flume. Since uniform flow is hardly achievable in such condi- 72 tions, roughness was obtained from the headloss in the chan- 73 nel. Therefore, the accuracy of the measured differences be- 74 tween upstream and downstream levels was crucial. This ac- 75 curacy is affected by the fixed error between the gauges (incer- 76 tainty estimated lower than $0.5 \mathrm{~mm}$, thanks to precision level- 77 ling with still water), and by the reading of levels during ex- 78 periments. The effect of water fluctuations was analyzed by 79 different means: pressure level sensors (Keller 46X/0.1Bar, ac- 80 curacy $0.01 \%$ of full scale in the range of the experiments) and digital cameras. The analysis showed that most incertainties 81 were due to water fluctuations $( \pm 1 \mathrm{~mm})$ observed at the free surface. Since flows are clearly subcritical, these fluctuations were ${ }_{83}$ rather limited, but they induced an incertainty between 1 and ${ }_{84}$ $2 \mathrm{~mm}$ on the measured headloss. The lowest incertainties could ${ }_{85}$ be achieved by increasing the number of readings, which was essential for configurations with the lowest headloss (around ${ }_{87}$ $5 \mathrm{~mm}$ between most distant gauges). Water depths ranged from ${ }_{88}$ 18.9 to $26.7 \mathrm{~cm}$ over all experiments. Mean velocities ranged between 0.26 and $0.38 \mathrm{~m}_{\mathrm{s}} \mathrm{s}^{-1}$. Manning roughness coefficient ${ }_{89}$ of the empty channel was estimated by removing all plants. A value of $0.02 \pm 0.005 \mathrm{~s} . \mathrm{m}^{1 / 3}$ was obtained for both reference dis- ${ }^{90}$ charges.

Six targets were fixed on channel curbstones to align TLS ${ }^{92}$ scans. Position of targets and gauges were precisely located ${ }^{93}$ using a tacheometer at a $0.5 \mathrm{~mm}$ accuracy.

\subsection{Plant material}

Four plant species were selected according to their hydrophilic behaviour on a gradient from xerophylous (Asparagus acuti- ${ }^{98}$ folius) to hydrophylous (Lythrum salicaria) wich is in accor- ${ }^{99}$ dance with their upstream-dowstream location in the drainage ${ }^{100}$ network, branching complexity and their abundance in ditches ${ }^{10}$ of the Southern France landscapes (Marnotte \& Carrara, 2006): Asparagus acutifolius, Lythrum salicaria, Elytrigia repens, and ${ }^{102}$ Scirpoides holoschoenus, these last two species being consid- ${ }^{103}$ ered as herbaceous, while the two others can be considered as ${ }^{104}$ sclerophyllous (Figure 3). In order to get correct estimates of ${ }^{105}$ plant densities in real ditches, a sampling campaign was con-106 ducted in the Languedoc area $(43.478 \mathrm{~N}, 3.338 \mathrm{~W})$ in $\mathrm{March}^{107}$ 2013 to estimate the vegetation densities for all species in simi- ${ }^{108}$ lar channels by counting total plant number per $0.48 \mathrm{~m}^{2}$ quadrat ${ }^{109}$ in eight sites, leading to a density of $170 \pm 100$ plants. ${ }^{-2}$ (Benitou, 2013).

Approximately 1600 plants of each species were collected in the Languedoc area just before experiments to prevent dessication and keep the initial roughness properties of plant material. Then each plant was cut at the basis to get calibrated $40 \pm 5 \mathrm{~cm}$ length replicates, i.e. above the water depths of the setup, leading to a determination of flow resistance in case of non-submerged vegetation (Järvelä, 2004).

According to Jalonen \& Järvelä (2014); Weissteiner et al. (2015), properties of plants are described in terms of projected areas, architecture and leaf to stem area ratios. Ten random samples of each plant were photographed laterally against white background in still air, and then area and stem parts were digitized from the scaled pictures to determine vegetation properties (Table 1). We conserved ramification variabilities occuring in the field. Only herbaceous plants were sometimes ramified, with a maximal axis order between 1 and 3 for Lythrum salicaria and between 2 and 3 for Asparagus acutifolius (axis order is determined according to rules of the Multi-scale Tree Graph formalism (Godin \& Caraglio, 1998). Each Elytrigia repens sampled consisted in one main shoot and one or two tillers, figuring herbaceous tillering. Each Scirpoides holoschoenus sample consisted in only one main shoot.

\subsection{Tested vegetation densities}

Five increasing vegetation densities were settled at the channel bottom, with various plant densities for a regular pattern along channel width and staggered along channel length, varying respectively from 0 to $41,82,164$ and 328 plant . $^{-2}$. The corresponding nearest distances between plants varied from 14 , 10,7 , and $5 \mathrm{~cm}$, respectively, in line with the variabilities observed in the field.

\subsection{Estimation of plant reconfiguration in flow}

According to Weissteiner et al. (2015), plant reconfiguration could be estimated by the underwater frontal projected area (FPA), giving deflected height and contracted width of the plant. Mounting cameras underwater at a distance preventing hydraulic artefacts and allowing plants observations under small water depths was not possible in our setup with small water depths. However, two cameras disposed on channel upstream and downstream borders and a third camera was located at nadir 6 meters above the channel with vertical recording position (cameras and gauge positions were illustrated in Figure 1). This allowed us to observe qualitatively if plant reconfiguration occurs during flow.

\subsection{Data clouds measure}

Data clouds were measured in absence of flow using a 1064 nm terrestrial lidar scanner (TLS) branded RIEGLC)VZ400 located at nadir 5 meters above the channel with vertical scan position at mid length to prevent too high incident angles. The RIEGLC)VZ400 a spot size of $4 \mathrm{~mm}$, a scan rate up to 700,000 points/s, and a range up to $200 \mathrm{~m}$. The selected field of view for the experiment was $80^{\circ} \times 160^{\circ}$ and the horizontal and vertical 


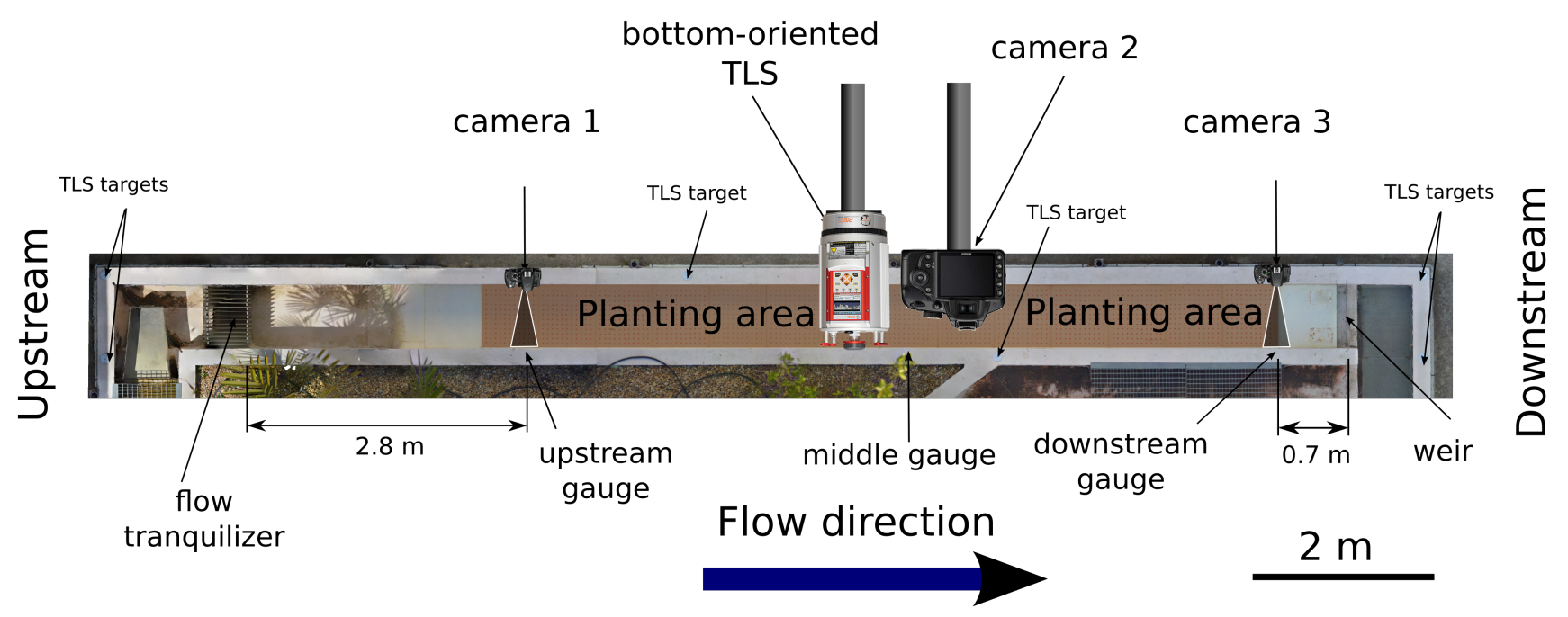

Figure 1: Vertical view of the experimental setup.

\begin{tabular}{l|c|c|c|c|c}
\hline Plant species & Basal stem diameter $(\mathrm{cm})$ & Plant height $(\mathrm{cm})$ & Plant width $(\mathrm{cm})$ & Frontal projected area $(\mathrm{FPA})\left(\mathrm{cm}^{2}\right)$ & Leaf to steam area ratio \\
\hline Asparagus acutifolius & $0.28(0.16-0.36)$ & $41.5(29-48)$ & $25.2(9-47)$ & $172.1(86-248)$ & $2.45(2.2-2.7)$ \\
Elytrigia repens & $1.01(0.9-1.2)$ & $45.5(35-57)$ & $24.2(16-35)$ & - \\
Lythrum salicaria & $0.63(0.4-0.8)$ & $42.1(37-45)$ & $16.0(8-20)$ & $185.7(26-366)$ \\
Scirpoides holoschoenus & $0.47(0.43-0.54)$ & $40.6(38-45)$ & $5.7(3-11)$ & $19.4(16-25)$ & $0.62(0.2-1.1)$ \\
\hline
\end{tabular}

Table 1: Table representing the mean geometric characteristics of the plant species over ten samples. Values in brackets correspond to the min-max. Note that the leaf to stem area ratio was not calculated for herbaceous species (indicated by a -)
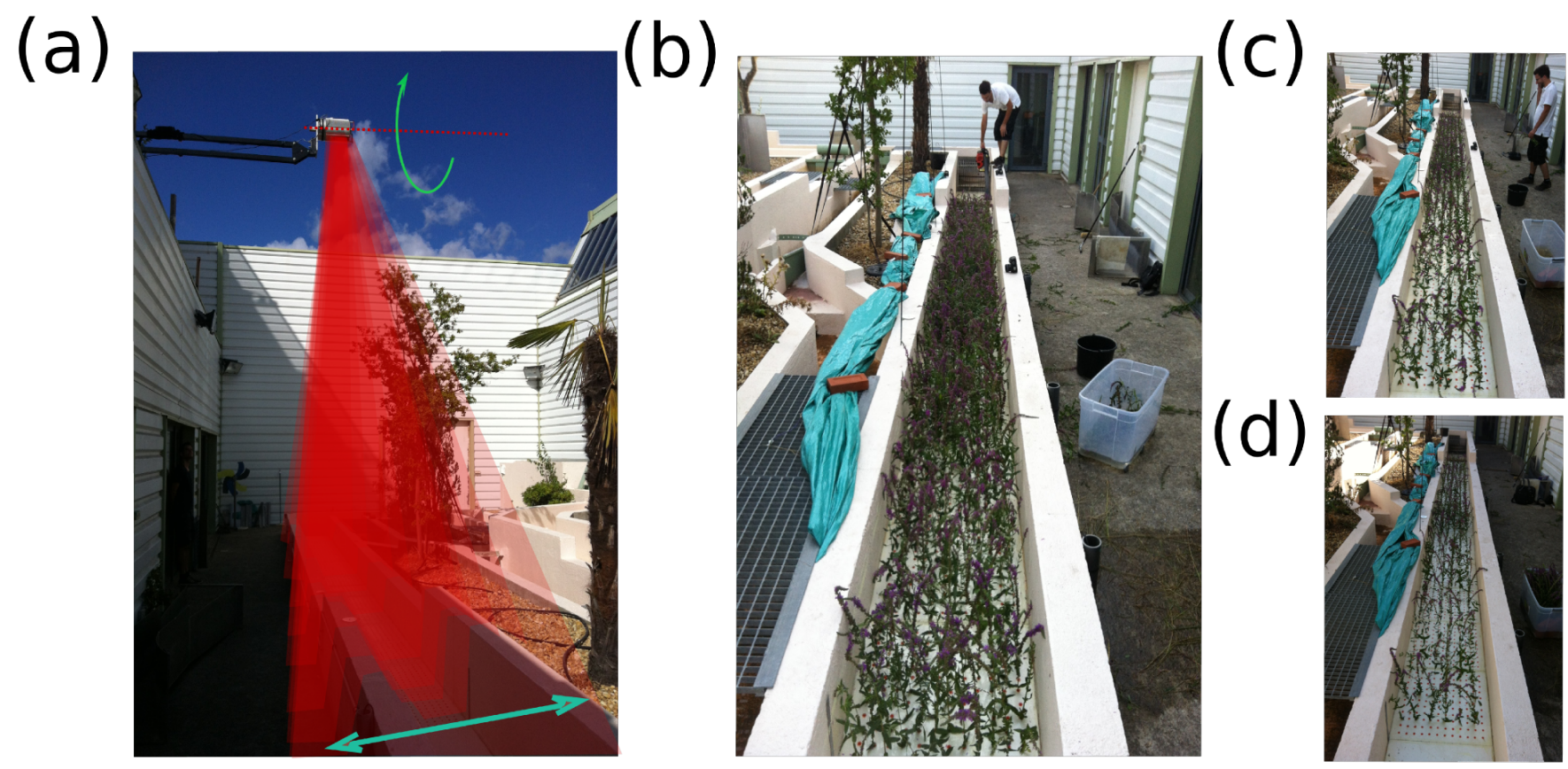

Figure 2: Illustration of the experimental setup. (a) the laser scanner and its scanning view (in red) through the channel flume. (b), (c), and (d) an example of species planting (Lythrum salicaria) at densities of $41,82,164$ plants. $m^{-2}$, respectively. 


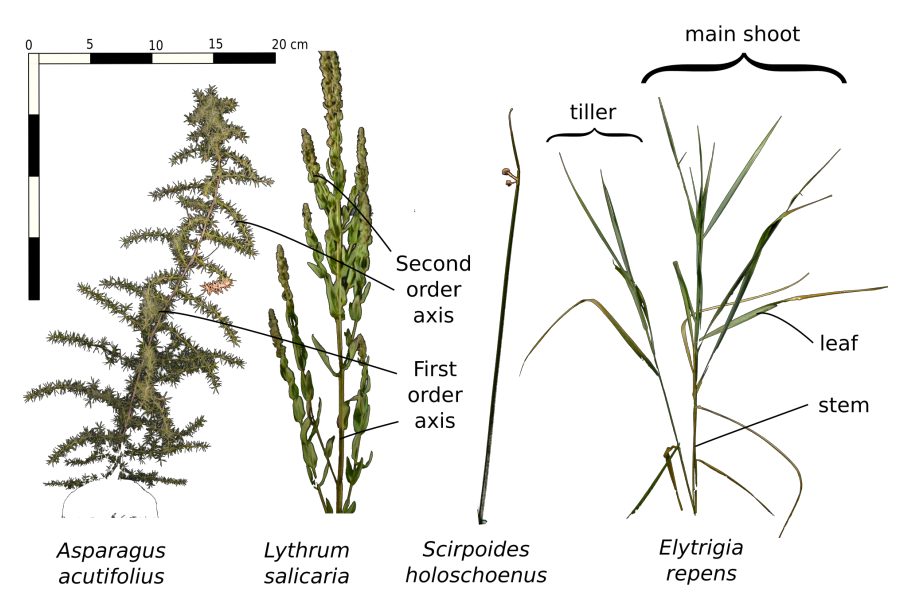

Figure 3: Illustration of the shape of selected species for the experiments.

increments were both set to $0.04^{\circ}$, giving a scanning resolution of $7 \mathrm{~mm}$ at a distance of $10 \mathrm{~m}$, corresponding to the range accuracy and precision of the scanner at this distance. TLS values were compared to manual measurements described in Table 1 only for vegetation height and FPA. The other variables cannot be accessed via the TLS clouds since cloud density was not ${ }^{36}$ high enough to identify a single plant architecture. Vegetation heights were directly issued from the cloud z-values, whereas ${ }^{37}$ FPA $\times$ planting density and FPA $\times$ number of plants rows along ${ }_{38}$ channel width were deduced from the computation of $B f_{1}$ and $B f_{2}$, respectively, as explained below.

We planted each combination of plant $\times$ density and we ${ }^{40}$ carried a first TLS scan. Then we opened the first sluice gate corresponding to a flow of 25.3 L.s ${ }^{-}$. After the steady flow ${ }^{41}$ was reached, measurements were taken, then we repeated the ${ }_{43}^{42}$ operation for the second flow corresponding to 51.4 L.s ${ }^{-} 1$.

\subsection{Blockage factor estimates}

TLS scans were first exported in referenced XYZ point cloud using Riscan Pro@software. Data clouds issued from the scans were scaled in the same local projection system to get length and width of the channel along $\mathrm{X}$ and Y-coordinates, respec- ${ }^{46}$ tively (see Figure 4 for definition of axes). Point clouds were ${ }^{47}$ first decimated using a mean nearest-neighbour distance filter ${ }^{48}$ and then voxelised using a voxelisation procedure illustrated in ${ }^{49}$ Figure 3 and similar to Jalonen et al. (2015)' approach. We de- ${ }^{50}$ fined a voxel resolution (here $1 \mathrm{~mm}^{3}$ ) able to discriminate plant organs from TLS noise. Next $\mathbb{1}_{x, y, z}$ denotes the indicator func- ${ }^{51}$ tion with 1 value when the TLS points are intercepted by the voxel, and 0 otherwise.

Then, we defined the density per voxel as $d_{y, z}$ by summing ${ }^{53}$ each voxels along $\mathrm{X}$-axis and we divided by the total number of ${ }_{54}$ voxels along the channel length $k$ to have a probability between 55 0 (no blockage) to 1 (complete blockage) (Equation 1) :

$$
d_{y, z}=\frac{\sum_{x=1}^{k} \mathbb{1}_{x, y, z}}{k}
$$

where,

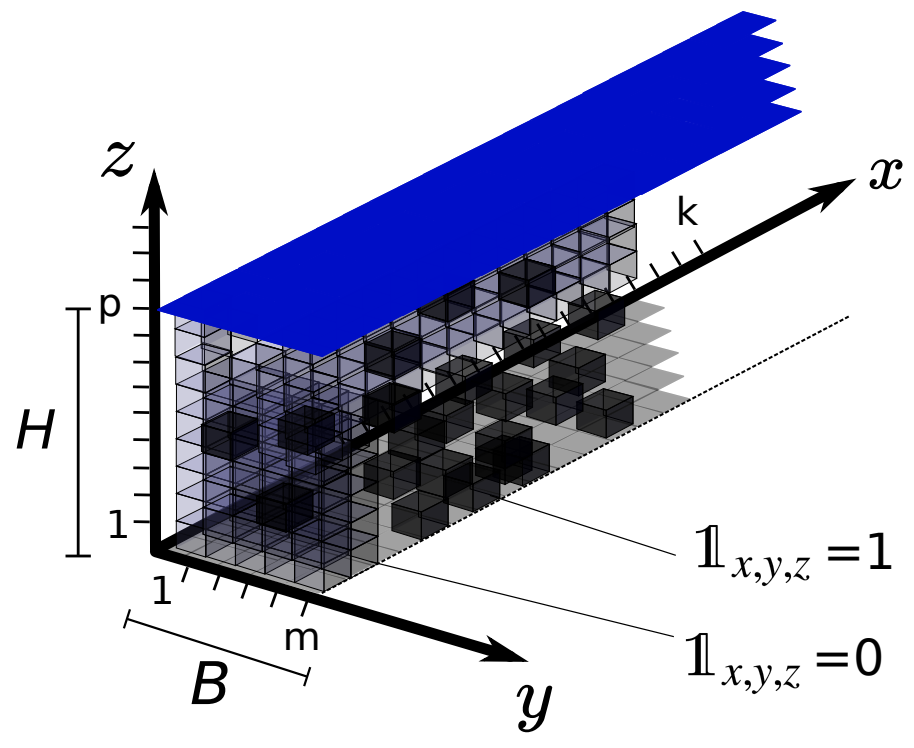

Figure 4: Illustration of point cloud voxelisation across the channel. $H$ corresponds to the water level (in blue). Black and transparent voxels correspond to cubes that contained or not points issued from point cloud, respectively.

- $x$, the position index of the voxel along the channel length

- $y$, the position index of the voxel along the channel width

- $z$, the position index of the voxel along the channel depth

We derived from the calculation of $d_{y, z}$ three possible definitions of the blockage factor $B f$ :

$B f_{1}$ : the mean $d_{y, z}$ in a cross section (Equation 2). This blockage factor corresponds to the volume blockage factor as defined by Fisher (1992). $B f_{1}$ is proportional to the FPA of each plant $\times$ planting density (Jalonen \& Järvelä (2014)).

$$
B f_{1}=\frac{\sum_{z=1}^{p} \sum_{y=1}^{m} d_{y, z}}{m \times p}
$$

$B f_{2}$ : the mean $B f_{1}$ thresholded in selected and non selected pixels (Equation 3). The $B f_{2}$ is similar to the frontal projected area of Jalonen \& Järvelä (2014) over the whole channel. In other words, $B f_{2}$ is proportional to the FPA of each plant $\times$ number of plants rows along y-axis.

$$
B f_{2}=\mathbb{1}_{B f_{1}>s}
$$

$B f_{3}$ : the maximal height $z$ of binarized $d_{x, z}$ according to the threshold $s$, summed over the channel width (Equation 4). $B f_{3}$ is computed with all voxels beyond the canopy of the thresholded point cloud equal to $1 . B f_{3}$ is thus computed from the mean canopy height model.

$$
B f_{3}=\frac{\sum_{y=1}^{m} z_{\max }\left(d_{y, z}>s\right)}{m \times p}
$$

where, 
- $B f_{x}$, denotes a given Blockage factor metrics for point cloud.

- $k, m, p$ denotes the number of voxels along $x, y$ and $z$ dimensions of the channel, respectively.

- $s$, denotes the threshold for $d_{y, z}$ binarization.

Here, the threshold value $s$ was fixed to the $Q_{0.05}$ percentile of the $d_{y, z}$ distribution. According to the usual Wald confidence level on parameters, we chose to eliminate $5 \%$ of the lower extreme value of $d_{y, z}$ and considered the $5 \%$ percentile as the ${ }^{46}$ threshold for noise-free significant density.

\subsection{Estimation of water flow resistance}

Manning coefficients were estimated from the measured to- ${ }^{50}$ tal head loss between upstream and downstream ends of the ${ }^{51}$ vegetated reach. To do so, we considered the backwater curve ${ }^{52}$ equation, expressed in its differential form:

$$
\frac{d H}{d x}=\frac{S_{b}-S}{1-F^{2}}
$$

with

$$
S=\frac{n^{2} Q^{2}}{B^{2} H^{2} R^{4 / 3}}
$$

in which $S_{b}$ is the bed slope, $S$ is the friction slope, $n$ is the ${ }^{61}$ Manning parameter, $Q$ is the discharge, $B$ the canal width, $R$ the ${ }^{62}$ hydraulic radius, $H$ the water height, and $F$ the Froude number. ${ }^{63}$ Equation 5 was solved by imposing the downstream boundary ${ }^{64}$ condition with the measured value at the downstream gauge, ${ }^{65}$ and the Runge-Kutta $4^{\text {th }}$ order approximation. Manning $n$ was ${ }^{66}$ obtained by minimizing the error between calculated and observed backwater curve.

\subsection{Relation between blockage factor and flow resistance}

Based on non-linear nature of Manning-Blockage factors ${ }^{70}$ relationships (Green, 2005a), we linked the blocage factors $B f_{x}{ }^{71}$ calculated to Manning coefficients using a simplified version of ${ }^{72}$ Nepf (2012) equation:

$$
n=a \times\left(1-B f_{x}\right)^{-b} \times H^{(1 / 6)}
$$

Non-linear Gauss-Newton fitting algorithm was used on Equa tion 7 to fit the $a$ and $b$ parameters.

\section{Results}

\subsection{Blockage factor estimation at channel scale}

Considering each species individually (Figure 5), sclero- ${ }^{82}$ phyllous plants such as Asparagus acutifolius and Lythrum sali- 83 caria had the highest levels of $d_{y, z}$. Herbaceous plants such 84 as Elytrigia repens presented a vertical heterogeneity due to 85 the presence of several blades from each plant sucker laying 86 on the ground, unlike to Scirpoides holoschoenus that exhib- 87 ited a higher rigidity level. Despite presenting occlusions for 88 the sclerophyllous species due to a single scan position, TLS 89 point clouds gave consistent images of expected $d_{y, z}$ for each 90

\begin{tabular}{l|l|r|r|r|r}
\hline Blockage factor & Parameter & Estimate & Std. Error & t value & $\operatorname{Pr}(>|t|)$ \\
\hline Bf1 & a & 0.06 & 0.01 & 8.93 & 0 \\
$(0-2 \mathrm{e}-04)$ & $\mathrm{b}$ & 5492.28 & 693.77 & 7.9 & 0 \\
\hline Bf2 & $\mathrm{a}$ & 0.09 & 0.01 & 10.67 & 0 \\
$(0-0.24)$ & $\mathrm{b}$ & 3.12 & 0.62 & 5.1 & 0 \\
\hline Bf3 & $\mathrm{a}$ & 0.08 & 0.00 & 18.14 & 0 \\
$(0-0.98)$ & $\mathrm{b}$ & 0.27 & 0.02 & 13.5 & 0 \\
\hline
\end{tabular}

Table 2: Table representing the values of $a$ and $b$ estimated from Non linear Gauss-Newton fitting algorithm on Equation 7. Values in brackets correspond to the range of each calculated blockage factor $B f$.

species. The threshold value $s$ corresponding to $d_{y}, z Q_{0.05}$ percentile was $3.00 \mathrm{e}-4$.

Mean vegetation heights issued from TLS scans were underestimated by $5 \%$ compared to manual measurements of each singles plants. The range (min-max) of vegetation heights issued from TLS scans were similarly underestimated compared to manual measurements. $B f_{1}$ and $B f_{2}$ were correlated to FPA of each plant $\times$ plant density and FPA of each plant $\times$ number of plants rows along $\mathrm{y}$-axis with a $R^{2}=0.91$ and 0.79 , respectively (linear model, $\mathrm{P}$-value $<0.001, \mathrm{df}=12$ ). P-values of the intercepts of the linear models were both above $5 \%$, indicating an absence of shift from TLS and manual measurements.

Video analysis from the three cameras revealed no reconfiguration of the plants, excepting the Elytrigia repens species that exhibited a blending of both main shoot and tillers of 10 $\pm 2^{\circ}$ and $40 \pm 10^{\circ}$, for first and second flow, respectively. This blending effect resulted in a deflected height reduction of $2 \%$ and $23 \%$, respectively. We observed a small contraction of Elytrigia repens width with a bending of leaves toward flow direction, this qualitative observation being difficult to quantify regarding camera resolutions.

\subsection{Estimation of water flow resistance}

The calculated Manning coefficients were highly dependent on plant species, with the higher values of Manning for sclerophyllous species such as Lythrum salicaria and Asparagus acutifolius (Figure 6). The herbaceous plants Scirpoides holoschoenus and Elytrigia repens exhibited lower values of Manning. This may be explained partly by branching complexity which is higher in sclerophyllous species (Figure 3).

The relation between Manning and $B f_{3}$ illustrated in Figure 6 was clearly non-linear and was in accordance with the simplified Equation 7. The non-linear relationship was also applied to the other calculated blockage factors. Plantation density was also positively correlated to Manning coefficient for all species, as shown in Figure 6. The error bars for $n$ were obtained considering incertainties on level and discharge measurements.

\subsection{Relation between blockage factor and flow resistance}

Figure 7 showed that all Manning coefficients were well related to the blockage factors $\left(R^{2}\right.$ ranging between $0.6-0.9$, pvalue $<0.05$ ).

The models underestimated the highest values of $n$ for $B f_{1}$ and $B f_{2}$, that corresponded to Elytrigia repens species.

All estimated parameters of Equation 7 were significant, with similar values for each calculated blockage factors, except for $B f_{1}$, as denoted by Table 2 . Value of parameter $b$ was linked 


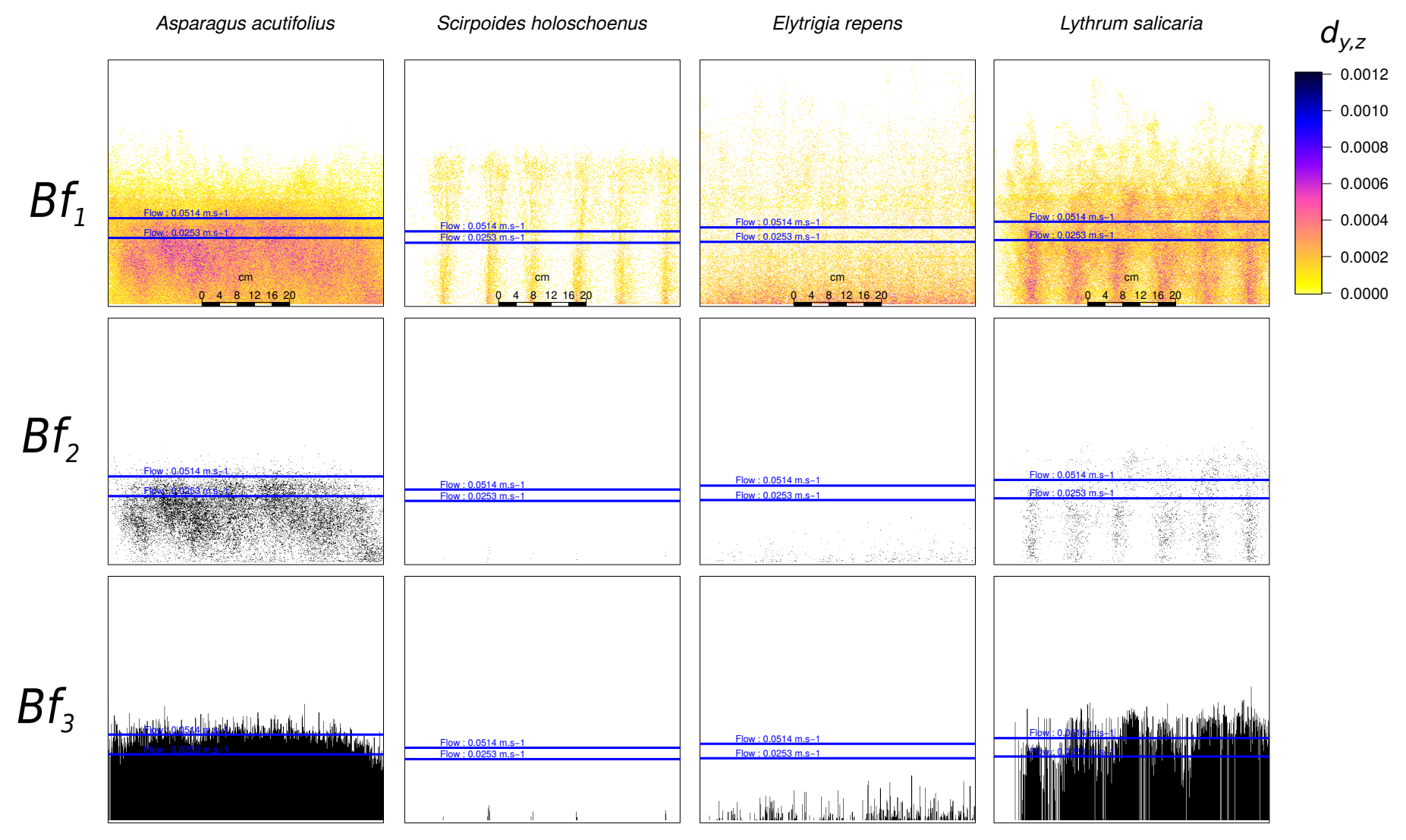

Figure 5: Description of calculated $d_{y, z}$ issued from point clouds voxelisation at $1 \mathrm{~mm}^{3}$ resolution. We illustrated the results for each species planted at 82 plants. $\mathrm{m}^{-2}$. Horizontal blue lines correspond to mean water level over the channel for the two different flows. First row corresponds to the illustration of $B f_{1}$ by pixel colors. Second and third rows correspond to the illustrations of $B f_{2}$ and $B f_{3}$, respectively. 


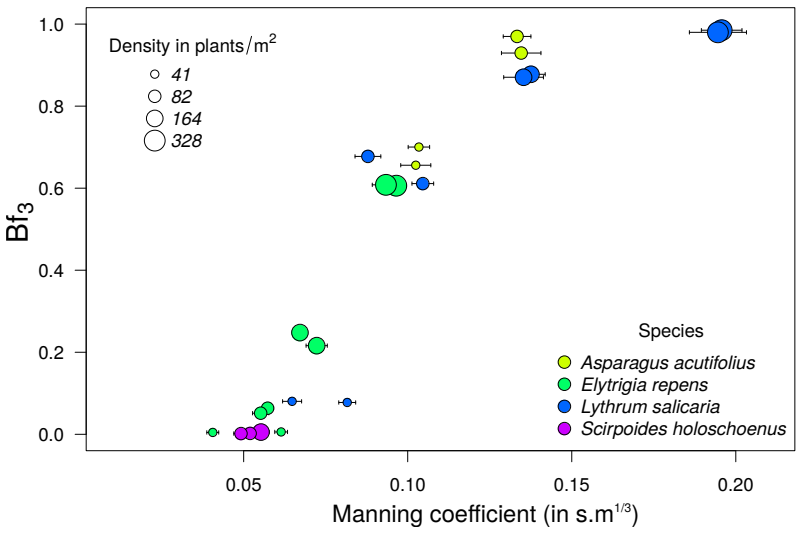

Figure 6: Relation between the calculated Manning $(n)$ and calculated blockage factor $B f_{3}$ for all species. Color and point size indicate a species and its density, respectively. Estimated errors issued from water depth variations were ${ }^{52}$ represented by horizontal segments.

derived from Luhar \& Nepf (2013). The consistence of Equation 7 with observed data, taking into account the non-linear nature of the $n-H$ and $n-B f_{x}$ relationships is in accordance with Green (2005b). The values of $b$, however, were substantially different from their estimated values 0.0239 given by (Luhar \& Nepf, 2013). $B f_{1}$ appears too small, which explains why $b$ must be set very large in this case.

The best model relating Manning coefficients to blockage factor were issued from Equation 7 applied to $B f_{3}$. It indicated that a measure of mean vegetation height could be sufficient to capture the resistance factor induced by vegetation cover, in accordance with results from Jalonen et al. (2015), provided that vegetation were uniformly distributed along the channel. The blockage factor $B f_{1}$ that corresponds to the volume blockage factor of (Fisher, 1992) gave better results for the low Manning coefficients, i.e. $n<0.1$, than $B f_{2}$ and $B f_{3}$, but failed to predict the high values of Manning. The thresold value $s$ fixed at $Q_{0.05}$ percentile of the total distributions of $d_{y}, z$ could explain that simulated Manning coefficients plateaued for values lower than 0.08 .

The underestimation of Manning factors for herbaceous plants could be due to spatial plant reconfiguration against flow that limits friction factors (Whittaker et al., 2013; Poggi et al., 2009; Järvelä, 2005; Weissteiner et al., 2015). A further improvement of the blockage factor calculation should be to add a flexibility coefficient that reduced the potential blockage factor calculated without flow. This improvement could be adapted from observations in towing tanks from Weissteiner et al. (2015) on foliated trees, but with a reduced distance of underwater cameras from plants to get sufficient resolution level for deflection and contraction measures of plants.

\section{Acknowledgments}

Authors are grateful to the ONEMA and the INRA institutions who both funded the experimental work exposed in this paper within the 'Fossés Infiltrants et Pesticides' project (ONEMA) and the 'Pari-Scientifique: Hydro-écologie des fossés agricoles' project (INRA-EA). Authors thank also David Combemale and Dénes Király for their help in the channel flume. Authors are grateful for reviewer constructive comments that considerably ameliorated first manuscript draft.

The authors declare that there is no conflict of interest regarding the publication of this paper.

\section{References}

Benitou, K. (2013). Végétation de fond de canal et rugosité: Test d'un nouveau protocole expérimental. Technical report, AgroParisTech, Montpellier, France.

Boothroyd, R. J., Hardy, R. J., Warburton, J., \& Marjoribanks, T. I. (2016). The importance of accurately representing submerged vegetation morphology in the numerical prediction of complex river flow. Earth Surface Processes and Landforms, 41(4), 567-576.

Cassan, L., Belaud, G., Baume, J., \& Dejean, C. (2015). Velocity profiles in a real vegetated channel. Environmental Fluid Mechanics, 15(6), 1263-1279.

Champion, P. D. \& Tanner, C. C. (2000). Seasonality of macrophytes and interaction with flow in a new zealand lowland stream. Hydrobiologia, 441(1), $1-12$. 
$\mathrm{Bf}_{1}$

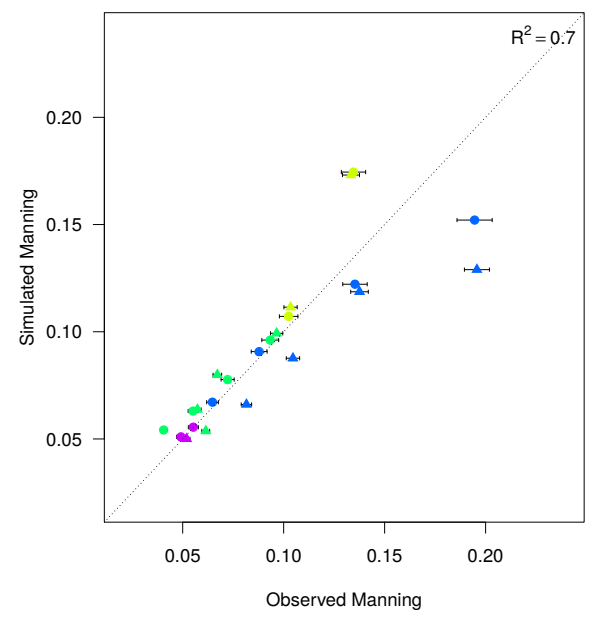

$\mathrm{Bf}_{2}$

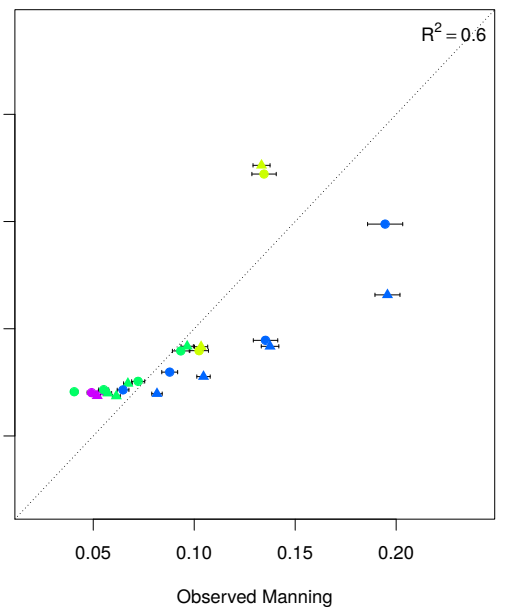

$\mathrm{Bf}_{3}$

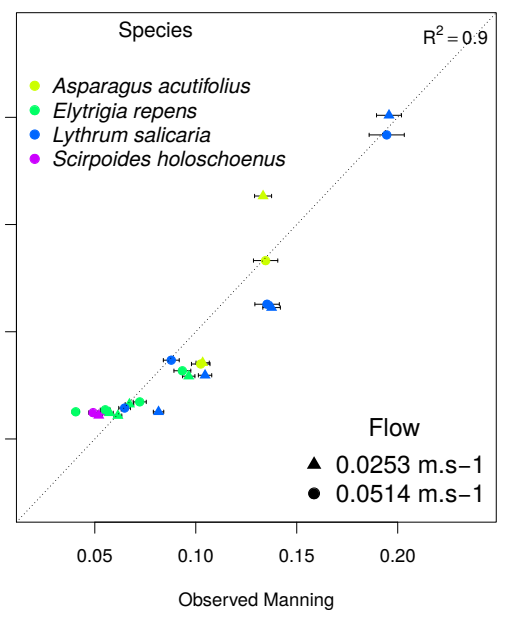

Figure 7: Comparison between observed Mannings and its simulated value using Equation 7 according to calculation of blockage factors from vegetation point clouds. Colors indicated the species, difference in flow values were symbolized by rounds and triangles. The dotted line corresponds to the perfect match between observations and simulations. Estimated errors issued from water depth variations were represented by horizontal segments.

Colbach, N., Collard, A., Guyot, S. H. M., Meziere, D., \& Munier-Jolain, N. 44 (2014). Assessing innovative sowing patterns for integrated weed manage- 45 ment with a 3d crop:weed competition model. European journal of agron- 46 omy, 53, 74-89.

Curran, J. C. \& Hession, W. C. (2013). Vegetative impacts on hydraulics and 48 sediment processes across the fluvial system. Journal of Hydrology, 505, 49 364-376.

Dollinger, J., Dagès, C., Bailly, J.-S., Lagacherie, P., \& Voltz, M. (2015). Man- 51 aging ditches for agroecological engineering of landscape. A review. Agron- 52 omy for Sustainable Development, 35(3), 999-1020.

Fisher, K. (1992). The hydraulic roughness of vegetated channels. Report SR, 54 305.

Folkard, A. M. (2011). Vegetated flows in their environmental context: a re- 56 view. Proceedings of the ICE - Engineering and Computational Mechanics, 57 164(1), 3-24.

Godin, C. \& Caraglio, Y. (1998). A Multiscale Model of Plant Topological 59 Structures. Journal of Theoretical Biology, 191(1), 1-46.

Green, J. C. (2005a). Comparison of blockage factors in modelling the resis- 61 tance of channels containing submerged macrophytes. River research and 62 applications, 21(6), 671-686.

Green, J. C. (2005b). Modelling flow resistance in vegetated streams: review and development of new theory. Hydrological processes, 19(6), 1245-1259. 65 Herzon, I. \& Helenius, J. (2008). Agricultural drainage ditches, their biological 66 importance and functioning. Biological Conservation, 141(5), 1171-1183. 67

Jalonen, J. \& Järvelä, J. (2014). Estimation of drag forces caused by natural 68 woody vegetation of different scales. Journal of Hydrodynamics, Ser. B, 69 26(4), 608-623.

Jalonen, J., Järvelä, J., \& Aberle, J. (2012). Leaf area index as vegetation 71 density measure for hydraulic analyses. Journal of Hydraulic Engineering, 72 139(5), 461-469.

Jalonen, J., Järvelä, J., Koivusalo, H., \& Hyyppä, H. (2014). Deriving flood- 74 plain topography and vegetation characteristics for hydraulic engineering 75 applications by means of terrestrial laser scanning. Journal of Hydraulic 76 Engineering, 140(11), 1-12.

Jalonen, J., Järvelä, J., Virtanen, J.-P., Vaaja, M., Kurkela, M., \& Hyyppä, H. 78 (2015). Determining Characteristic Vegetation Areas by Terrestrial Laser 79 Scanning for Floodplain Flow Modeling. Water, 7(2), 420-437.

Järvelä, J. (2004). Determination of flow resistance caused by 81 non [U+2010] submerged woody vegetation. International Journal of River 82 Basin Management, 2(1), 61-70.

Järvelä, J. (2005). Effect of submerged flexible vegetation on flow structure and 84 resistance. Journal of Hydrology, 307(1-4), 233-241.

Kattge, J., Díaz, S., Lavorel, S., Prentice, I. C., Leadley, P., Bönisch, G., Gar- 86 nier, E., Westoby, M., Reich, P. B., Wright, I. J., Cornelissen, \& al. (2011). TRY - a global database of plant traits. Global Change Biology, 17(9), 2905-2935.

Kouwen, N., Unny, T., \& Hill, H. M. (1969). Flow retardance in vegetated channels. Journal of the Irrigation and Drainage Division, 95(2), 329-344.

Lepart, J. \& Debussche, M. (1992). Human impact on landscape patterning: Mediterranean examples. In Landscape boundaries (pp. 76-106). Springer.

Levavasseur, F., Biarnès, A., Bailly, J., \& Lagacherie, P. (2014). Time-varying impacts of different management regimes on vegetation cover in agricultural ditches. Agricultural Water Management, 140(0), 14-19.

Luhar, M. \& Nepf, H. M. (2013). From the blade scale to the reach scale: A characterization of aquatic vegetative drag. Advances in Water Resources, 51, 305-316.

Marnotte, P. \& Carrara, A. (2006). Plantes des rizières de Camargue. Montpellier, France: Editions Quae. Google-Books-ID: T_JvqEx7RP4C.

Nepf, H. M. (2012). Hydrodynamics of vegetated channels. Journal of Hydraulic Research, 50(3), 262-279.

Nikora, V. (2010). Hydrodynamics of aquatic ecosystems: An interface between ecology, biomechanics and environmental fluid mechanics. River Research and Applications, 26(4), 367-384.

Nikora, V., Larned, S., Nikora, N., Debnath, K., Cooper, G., \& Reid, M. (2008). Hydraulic resistance due to aquatic vegetation in small streams: field study. Journal of hydraulic engineering, 134(9), 1326-1332.

Nikuradse, J. (1933). Strömungsgesetze in rauhen Rohren. VDI-Verlag.

Pasquino, V., Gualtieri, P., \& Doria, G. P. (2016). On evaluating flow resistance of rigid vegetation using classic hydraulic roughness at high submergence levels: An experimental work. In Hydrodynamic and Mass Transport at Freshwater Aquatic Interfaces (pp. 269-277). Springer.

Poggi, D., Krug, C., \& Katul, G. G. (2009). Hydraulic resistance of submerged rigid vegetation derived from first-order closure models. Water Resources Research, 45(10), 1-14.

Stephan, U. \& Gutknecht, D. (2002). Hydraulic resistance of submerged flexible vegetation. Journal of Hydrology, 269(1-2), 27-43.

Thomas, R. E., Johnson, M. F., Frostick, L. E., Parsons, D. R., Bouma, T. J., Dijkstra, J. T., Eiff, O., Gobert, S., Henry, P.-Y., Kemp, P., Mclelland, S. J., Moulin, F. Y., Myrhaug, D., Neyts, A., Paul, M., Penning, W. E., Puijalon, S., Rice, S. P., Stanica, A., Tagliapietra, D., Tal, M., Tørum, A., \& Vousdoukas, M. I. (2014). Physical modelling of water, fauna and flora: knowledge gaps, avenues for future research and infrastructural needs. Journal of Hydraulic Research, 52(3), 311-325.

Vargas-Luna, A., Crosato, A., \& Uijttewaal, W. S. (2015). Effects of vegetation on flow and sediment transport: comparative analyses and validation of predicting models. Earth Surface Processes and Landforms, 40(2), 157-176. 
1 Watson, D. (1987). Hydraulic effects of aquatic weeds in uk rivers. Regulated Rivers: Research $\mathcal{F}$ Management, 1(3), 211-227.

Weissteiner, C., Jalonen, J., Järvelä, J., \& Rauch, H. P. (2015). Spatial-structural properties of woody riparian vegetation with a view to reconfiguration under hydrodynamic loading. Ecological Engineering, 85, 85-94.

Whittaker, P., Wilson, C., Aberle, J., Rauch, H. P., \& Xavier, P. (2013). A drag force model to incorporate the reconfiguration of full-scale riparian trees under hydrodynamic loading. Journal of Hydraulic Research, 51(5), 569580 .

Wiens, J. A. (2002). Riverine landscapes: taking landscape ecology into the water. Freshwater Biology, 47(4), 501-515. 